\title{
Cutaneous Adverse Drug Reactions to Polyherbal Formulations - A Retrospective Study
}

\author{
Sandhya Somasekharan Nair ${ }^{1}$, Smitha Ancy Varghese ${ }^{2}$ \\ ${ }^{1}$ Assistant Professor, Department of Dermatology, Government Medical College, Thiruvananthapuram, Kerala, India. \\ ${ }^{2}$ Assistant Professor, Dermatology, Government Medical College, Thiruvananthapuram, Kerala, India.
}

\section{ABSTRACT}

\section{BACKGROUND}

Although considered natural, herbal therapies can cause allergic reactions and even potentially dangerous side effects. In this article, we address cases of cutaneous adverse drug reactions (CADR) which are possibly related to polyherbal formulations (PHF).

\section{METHODS}

A retrospective study of ten years was carried out where the case sheets of patients admitted in dermatology ward of a tertiary care centre with cutaneous drug reactions were reviewed. Cases with clinical diagnosis of CADR along with history of intake of PHF were analysed. Demographic data, clinical type of drug reaction, drug history and blood investigations were recorded. Naranjo score was done to determine causality.

\section{RESULTS}

28 out of 506 patients (5.53\%) where diagnosed with CADR possibly due to PHF (10 had maculopapular exanthema, 7 had exfoliative dermatitis, 4 cases had TEN, 2 had SJS, 2 had urticaria, and one patient each had DHS, angioedema, and fixed drug eruptions. Naranjo score of 5-6 implied 'possible' causality. Most were in the 30-40 years age group. Female to male ratio was $1.15: 1$. The commonest systemic association included hepatic involvement followed by renal involvement. All patients were treated with the withdrawal of the culprit drug and administration of systemic steroids and supportive measures. One patient with extensive TEN expired, thus giving a mortality rate of $3.4 \%$.

\section{CONCLUSIONS}

PHF have an untapped potential that should be utilised. However, these drugs need to be scrutinised in the same way as any modern drug, i.e., via randomised controlled clinical trials.

\section{KEY WORDS}

Cutaneous Adverse Drug Reactions, Polyherbal Formulations
Corresponding Author: Dr. Smitha Ancy Varghese, Villa No. 3, Pebble Gardens, Chembazhanthy, P. O. Trivandrum-695587, Kerala, India. E-mail: smitharijo@gmail.com

DOI: $10.14260 / j e m d s / 2019 / 579$

Financial or Other Competing Interests: None.

How to Cite This Article: Nair SS, Varghese SA. Cutaneous adverse drug reactions to polyherbal formulationsa retrospective study. J. Evolution Med. Dent. Sci. 2019;8(34):2662-2666, DOI: 10.14260/jemds/2019/579

Submission 02-07-2019, Peer Review 10-08-2019, Acceptance 17-08-2019, Published 26-08-2019. 


\section{BACKGROUND}

Ayurveda is a system of medicine originating from India that involves mainly two types of herbal formulations: Kasthoushadhies (pure herbal preparations) and Rasaoushadhies (herbo-bio-mineral metallic preparation), in which the former is the most widely prescribed, the reason being Rasoushadhies are known to contain heavy metals, some that are even potentially lethal poisons like arsenic, lead and mercury and therefore their use is limited these days. ${ }^{1}$ Though the purely herbal formulations are perceived to be safe as they are natural products, recent scientific research points out to the fact that many of these formulations are producing side effects such as allergic reactions, rashes, asthma, headaches, dizziness, agitation, dry mouth, seizures, fatigue, tachycardia, nausea, vomiting, and diarrhoea. ${ }^{2}$ Severe side effects have also been reported including cases of hepatotoxicity and fatal reactions like anaphylaxis. ${ }^{3}$ Ayurvedic literature contains various references to the occurrence and prevention of drug reactions, however such information is scattered and the compilation and analysis along with the modern concept of drug reactions is a significant need in present times. ${ }^{1}$ Though there are a handful of case reports where specific cutaneous adverse effects are documented to be caused by herbal medications, large studies in this area are limited. This tenyear retrospective study brings out the various cutaneous drug reactions encountered as a result of herbal medications observed among patients admitted with cutaneous adverse drug reactions (CADR).

\section{METHODS}

This was a retrospective observational study spanning a decade i.e. from January 2005 to December 2014. The study was approved by the Institutional Ethics committee (IEC No. $05 / 25 / 2014 /$ MCT) of our institution and was conducted according to the declaration of Helsinki.

The sources of the data were the patient case sheets that were retrieved from our institution. These case sheets were filled up earlier by dermatology post graduate students while on ward rounds and supervised by faculty during their clinical training at our institution. A total of 506 case sheets pertaining to cutaneous adverse drug reactions were utilised to procure the requisite data. Among them, patients who have taken poly herbal drugs in the recent past were considered for the study. The data collection form was customized to acquire data regarding ADRs. Cases where allopathic medications were co-administered were excluded from the study. A detailed proforma containing patients' details including demographic data, drug history, clinical history, past history and comorbidities were duly filled up. In order to identify the culprit drug, the factors like drug history, temporal correlation with the drug, duration of skin lesions, time interval between the drug intake and onset of rash, morphology of drug eruption, associated mucosal or systemic involvement and improvement of lesions on withdrawal of drug were carefully analysed. This was further confirmed by the history of improvement on the withdrawal of the same. The results of blood and urine investigations, liver function test, renal function test, random blood sugar and in relevant cases, chest X-rays and ultrasound abdomen were recorded. The various subtypes of CADR manifested in the study population and the associated systemic findings were studied. Causality assessment using Naranjo causality score ${ }^{4}$ was done and only those 'probable' and 'possible' cases on causality assessment were included in the study. It may be noted that we could not obtain cases of 'definite ADR', as drug rechallenge was not performed.

Statistical analysis was done after entering data into a Microsoft excel sheet. Two investigators cross-checked the data entry to ensure accuracy. The primary outcome variable was incidence of CADRs with polyherbal formulations as a probable cause. Incidence was estimated (In percentage) with number of patients with CADR with PHF as numerator and total number of CADR patients in dermatology ward as denominator. Subgroup analysis of incidence based on characteristics of study population (Age groups, genders) and expressed as median and ratio. The secondary outcome variables were pattern of CADRs (Their types, lag period, causative drugs, causality and outcomes were measured in percentages.

\section{RESULTS}

During the ten year study period, 28 out of 506 patients (5.53\%) who were admitted in the dermatology department with CADR with history of taking Ayurvedic drugs prior to onset of reactions had been selected for the study. Among the 28 patients, ten had maculopapular exanthema (35.7\%), seven had exfoliative dermatitis $(25 \%)$, four cases had Toxic Epidermal Necrolysis (TEN) (14\%), two had Steven Johnson's syndrome (SJS) (7\%) two had urticarial (7\%) and one patient each had Drug Hypersensitivity Syndrome (DHS), angioedema and fixed drug eruption (3.5\%). The youngest patient was three years old and the oldest was 75 years, with the median being the 30-40 age group. There were 15 males and 13 females with the male to female ratio of 1.15:1. Latent period between the drug intake and the onset of symptoms varied from 1-2 days in patients with urticaria- angioedema, 1 day to 6 weeks in cases of maculopapular exanthem, 7 days to 6 weeks in cases of exfoliative dermatitis, 7 days to 28 days in most patients with SJS- TEN complex while it was 14 days in the patient with DHS and within hours in case of the patient with FDE. The indications for which the alternative medication was taken along with the clinical type of CADR that they developed and the Naranjo score for each agent is depicted in Table 1 . The most common indication for which PHF were prescribed were for dermatological indications like dermatitis, psoriasis and vaginal discharge. This was followed by orthopaedic indications like joint pains and low backache. Twenty one patients gave a history of using only a single Ayurvedic drug prior to onset of reaction while seven patients had used multiple drugs. Six patients had received unlabelled polyherbal formulations. All cases had a Naranjo score of 5-6 which implies 'possible' causality.

On clinical examination, two patients had pallor and icterus, one patient (DHS) had lymphadenopathy and 12 patients had fever and constitutional symptoms. One patient had hepatomegaly alone and one (DHS patient) had 
hepatosplenomegaly. On routine blood examination, six patients had neutrophilia, eight patients had eosinophilia and nine patients had a raised ESR. On evaluating organ specific damage, hepatic involvement with ten patients showing elevated liver enzymes with three patients showing additional hyperbilirubinemia were observed. Four patients showed an altered renal function and hyponatremia was seen in three patients. Comorbidities noted in this study population includes cardiac disease in two patients, diabetes in one patient and carcinoma head of pancreas in one patient. Four patients in the study group gave history of drug reactions in the past to certain allopathic medications, but these drugs were not re-administered anytime in the recent past. Four patients had a personal history of atopy and six patients gave history of cutaneous adverse drug reactions in a close family member.

\begin{tabular}{|c|c|c|c|c|}
\hline $\begin{array}{l}\text { Sl. } \\
\text { No. }\end{array}$ & Indications & $\begin{array}{l}\text { Drugs } \\
\text { Taken }\end{array}$ & $\begin{array}{c}\text { Naranjo } \\
\text { Score } \\
\end{array}$ & $\begin{array}{c}\text { Type of } \\
\text { Drug RN } \\
\end{array}$ \\
\hline 1 & $\begin{array}{c}\text { Vaginal } \\
\text { discharge }\end{array}$ & $\begin{array}{l}\text { Single polyherbal } \\
\text { formulation }\end{array}$ & 5 & TEN \\
\hline 2 & Haemorrhoids & $\begin{array}{l}\text { Multiple polyherbal } \\
\text { formulations }\end{array}$ & 6 & Exanthem \\
\hline 3 & Conjunctivitis & $\begin{array}{c}\text { Unlabelled polyherbal } \\
\text { formulation }\end{array}$ & 6 & FDE \\
\hline 4 & Jaundice & $\begin{array}{l}\text { Multiple polyherbal } \\
\text { formulations }\end{array}$ & 5 & DHS \\
\hline 5 & Body weight & $\begin{array}{c}\text { Single polyherbal } \\
\text { formulation }\end{array}$ & 6 & Exfoliative dermatitis \\
\hline 6 & Injury & $\begin{array}{l}\text { Multiple polyherbal } \\
\text { formulations }\end{array}$ & 6 & Exanthem \\
\hline 7 & Body weight & $\begin{array}{l}\text { Single polyherbal } \\
\text { formulation }\end{array}$ & 6 & SJS \\
\hline 8 & Joint pain & $\begin{array}{c}\text { Unlabelled polyherbal } \\
\text { formulation }\end{array}$ & 6 & Exanthem \\
\hline 9 & Cardiac disease & $\begin{array}{c}\text { Unlabelled polyherbal } \\
\text { formulation }\end{array}$ & 5 & Exfoliative dermatitis \\
\hline 10 & Joint pains & $\begin{array}{l}\text { Multiple polyherbal } \\
\text { formulations }\end{array}$ & 6 & Exanthem \\
\hline 11 & Psoriasis & $\begin{array}{l}\text { Multiple polyherbal } \\
\text { formulations }\end{array}$ & 6 & Exanthem \\
\hline 12 & Joint pain & $\begin{array}{c}\text { Unlabelled polyherbal } \\
\text { formulations }\end{array}$ & 6 & Exanthem \\
\hline 13 & Haemorrhoids & $\begin{array}{l}\text { Single polyherbal } \\
\text { formulation }\end{array}$ & 6 & Exanthem \\
\hline 14 & Headache & $\begin{array}{l}\text { Single polyherbal } \\
\text { formulation }\end{array}$ & 6 & SJS \\
\hline 15 & Joint pain & $\begin{array}{l}\text { Multiple polyherbal } \\
\text { formulations }\end{array}$ & 5 & Exfoliative dermatitis \\
\hline 16 & Abortion & $\begin{array}{c}\text { Unlabelled polyherbal } \\
\text { formulation }\end{array}$ & 6 & Exanthem \\
\hline 17 & $\begin{array}{c}\text { Atopic } \\
\text { dermatitis }\end{array}$ & $\begin{array}{c}\text { Unlabelled polyherbal } \\
\text { formulation }\end{array}$ & 6 & Urticaria \\
\hline 18 & Acrodermatitis & $\begin{array}{l}\text { Multiple polyherbal } \\
\text { formulations }\end{array}$ & 6 & Exanthem \\
\hline 19 & Fever & $\begin{array}{l}\text { Single polyherbal } \\
\text { formulation }\end{array}$ & 6 & Urticaria \\
\hline 20 & Fever & $\begin{array}{l}\text { Single polyherbal } \\
\text { formulation }\end{array}$ & 6 & Exanthem \\
\hline 21 & Body weight & $\begin{array}{c}\text { Single polyherbal } \\
\text { formulation }\end{array}$ & 6 & TEN \\
\hline 22 & URI,Backache & $\begin{array}{c}\text { Unlabelled polyherbal } \\
\text { formulation }\end{array}$ & 6 & Angioedema \\
\hline 23 & Headache & $\begin{array}{l}\text { Single polyherbal } \\
\text { formulation }\end{array}$ & 6 & TEN \\
\hline 24 & $\begin{array}{l}\text { Plantar } \\
\text { psoriasis }\end{array}$ & \begin{tabular}{|c|} 
Guggulatiktakam \\
kashayam \\
Triphalachurnam(LA)
\end{tabular} & 6 & Exfoliative dermatitis \\
\hline 25 & Backache & $\begin{array}{l}\text { Single polyherbal } \\
\text { formulation }\end{array}$ & 6 & Exfoliative dermatitis \\
\hline 26 & Eczema & $\begin{array}{l}\text { Multiple polyherbal } \\
\text { formulation }\end{array}$ & 5 & Exfoliative dermatitis \\
\hline 27 & Jaundice & $\begin{array}{l}\text { Single polyherbal } \\
\text { formulation }\end{array}$ & 5 & TEN \\
\hline 28 & Eczema & $\begin{array}{c}\text { Unlabelled polyherbal } \\
\text { formulation }\end{array}$ & 5 & Exfoliative dermatitis \\
\hline
\end{tabular}

Table 1. Various Types of Drug Reactions, Indications for Which They

Were Given and Naranjo Score

All the patients were treated with the withdrawal of the culprit drug and administration of $1-2 \mathrm{mg} / \mathrm{kg}$ body weight of prednisolone or betamethasone equivalent when needed, along with supportive measures. Two patients one with exfoliative dermatitis and the other with maculopapular exanthem recovered with only supportive measures. The only patient who didn't improve was a 19-year-old female who suffered TEN following Ayurvedic drug taken for vaginal discharge. She had widespread erosions, developed sepsis, liver derangements, metabolic acidosis and hyponatremia and expired on the $7^{\text {th }}$ post-admission day in spite of administering high dose steroids and broad-spectrum antibiotics, thus contributing to a mortality rate of $3.5 \%$ among the patients with CADR to Ayurvedic drugs in this study group. All other patients had relief of symptoms and were discharged with an average hospital stay of 12 days.

\section{DISCUSSION}

ADRs play an important role in assessing drug safety in any system of medicine. Although, Ayurvedic literature has described the eventuality and reasons for drug reactions along with preventive measures, lack of documentation and thereby underreporting of these events pose a major setback. $^{5}$

In this study, we found that $5.5 \%$ of all patients admitted with CADR during a ten year period, had polyherbal formulations implicated as a cause. Other studies and case reports have also implicated polyherbal agents as a cause for CADR. ${ }^{6}$

Most patients were in the $30-40$ age group, a similar pattern also being observed in other studies on CADR.7,8 There was a slight male preponderance noticed in this study though similar studies in Indian patients show both male and female preponderance.9,10 CADRs can assume various morphological patterns. Studies by Sharma et $\mathrm{al}^{7}$ and Nanda et al ${ }^{9}$ showed maculopapular exanthem as the commonest morphological pattern of CADR with allopathic drugs, the same pattern was also noticed in this study with maculopapular exanthem being the most common reaction ( 35\%) followed by Exfoliative dermatitis and SJS-TEN. Among the 179 patients who presented with Severe cutaneous adverse reactions (SJS- TEN and DHS), seven patients (3.9\%) had polyherbal drugs as a cause. Though rare, serious drug reactions like SJS and TEN have been documented to follow intake of herbal medications. ${ }^{11}$

The most common indications for which PHFs were prescribed in this study included dermatological conditions like dermatitis and psoriasis. In India, herbal preparations containing neem leaves (Azadirachta indica), turmeric (Curcuma longa) and guggula (Commiphera wightianna) are being widely used as treatment for inflammatory skin diseases with occasional reports of contact dermatitis. ${ }^{12}$ The other indications for which PHF were used in our study included joint pain, backache, head ache and improving body weight. In our country it is commonly observed that these herbal medicines are prescribed for a wide variety of nonspecific conditions like improving vitality, anti-stress effects, boosting immunity and increasing appetite or memory.

The Naranjo Scale, or Naranjo Nomogram was used in this study to determine causality. This scale was developed to help standardise assessment of causality for all adverse drug reactions. The scale was also designed for use in controlled 
trials and registration studies of new medications, rather than in routine clinical practice. Nevertheless, it is simple to apply and widely used. The Score consists of 10 questions that are answered as either Yes, No, or "Do not know". Different point values $(1,-1$ or 0$)$ are assigned to each answer.

The questionnaire included the following 10 questions-

- Are there previous conclusive reports of this reaction?

- Did the adverse event appear after the drug was given?

- Did the adverse reaction improve when the drug was discontinued or a specific antagonist was given?

- Did the adverse reaction reappear upon readministering the drug?

- Were there other possible causes for the reaction?

- Did the adverse reaction reappear upon administration of placebo?

- Was the drug detected in the blood or other fluids in toxic concentrations?

- Was the reaction worsened upon increasing the dose? Or, was the reaction lessened upon decreasing the dose?

- Did the patient have a similar reaction to the drug or a related agent in the past?

- Was the adverse event confirmed by any other objective evidence?

Total scores range from -4 to +13 ; the reaction is considered definite if the score is 9 or higher, probable if 5 to 8 , possible if 1 to 4 , and doubtful if 0 or less. ${ }^{4}$ This study showed causality ranging from 5-6 which indicates 'probable' causality. One of the limitations of this study was that drug re-challenge could not be done as a result a higher score confirming a 'definite' causality was not obtained.

The most common system affected apart from skin, was the gastrointestinal system, with hepatotoxicity being the most pronounced characterised by the elevated liver enzymes and hyperbilirubinemia. Both, natural and synthetic chemicals are foreign products to the body and need metabolic degradation to be eliminated. During this process, hepatotoxic metabolites may be generated causing liver injury in susceptible patients and even lead to acute liver failure in certain cases. ${ }^{13}$ This study also revealed an altered renal function in 4 patients (14\%).There are reported evidences of nephrotoxicity of many herbs or herbal products, attributed either to the inherent properties of the herb or factors such as herb-drug interactions, mistakes in dosage and identification, and contaminants within the mixture. ${ }^{14}$ One patient, who developed TEN following Ayurvedic drug taken for vaginal discharge had succumbed to sepsis, metabolic acidosis and hepatotoxicity. Severe disease leading to mortality (4.8\%) were reported in a study that was done on traditional Chinese polyherbal medications. ${ }^{15}$ Also in a study from south India, mortality following drug induced liver injury has been reported, especially when drugs contained heavy metals and hepatotoxic volatile organic compounds (hVOCs). ${ }^{16}$ Ayurvedic practitioners vouch on the efficacy and safety of these products but also suggest procurement of herbs mix must be only from reputable sources. Formulations purchased from a non-reputable manufacturers may contain additives or toxins which may result in the adverse effects upon consumption. Also standardisation of herbs relative to the active compounds is rarely performed thereby causing intrinsic variability resulting in products that may be quite different and not necessarily bioequivalent even when prepared from the same single herbal ingredients. ${ }^{17}$

Another observation in this study was the fact that unlabelled polyherbal formulations were taken prior to drug reactions in 6 cases. Despite the fact that the manufacture and marketing of Ayurvedic drugs is covered by the Drugs and Cosmetics Act 1940, there are Ayurvedic practitioners who prepare medicines for their patients themselves. This informal sector undertake manufacturing and selling ayurvedic drugs on a small-scale in the form of unlabelled packets and containers often making it impossible to identify the ingredients in the preparation. ${ }^{18}$

Herbal drugs, in most developed countries follow strict pharmacovigilance obligations under specific directives and additional National regulations. In India AYUSH, a Government undertaking established in 2013, encompassing Ayurveda, Yoga, Unani, Siddha and Homeopathy, has started regulating Ayurvedic companies for quality control and standardization of herbs, improving research and development and the availability of raw materials, and monitoring the education standards of Ayurvedic colleges. ${ }^{19}$ However, the protocols for quality control in terms of the purity, shelf life, and efficacy of the medicines needs to be perfected. Given that a vast majority of the population in India still depend on PHF for various ailments, the paucity of reports of adverse drug reactions to them is surprising and suspicious. One factor may be attributed to the uncertainty in ascribing causality, especially when using multi-ingredient and often unlabelled products. The lack of investigational and financial resources, the inability to obtain comprehensive medical history due to patient ignorance or reluctance to divulge pertinent information, and the relative unfamiliarity of Complementary and Alternative medicinal products among mainstream health care providers often lead to a missed diagnosis. ${ }^{20}$

\section{CONCLUSIONS}

It is acknowledged that Ayurveda as a whole has untapped potential that should be utilised. However, it requires thorough search for medicinal plants, proper guidelines for their identification, validation of the scientific methods of isolation of active ingredients, pre-clinical evaluation of their pharmacological and toxicological profiles, clinical evidence of their usefulness and generating data regarding safety in post marketing studies as well. In other words, these drugs need to be scrutinised in the same way as any modern drug, i.e., via randomised controlled clinical trials.

\section{REFERENCES}

[1] Parasuraman S, Thing GS, Dhanaraj SA. Polyherbal formulation: concept of ayurveda. Pharmacogn Rev 2014;8(16):73-80.

[2] Ernst E. The risk-benefit profile of commonly used herbal therapies: Ginkgo, St. John's Wort, Ginseng, Echinacea, Saw Palmetto, and Kava. Ann Intern Med 2002;136(1):42-53. 
[3] Stickel F, Patsenker E, Schuppan D. Herbal hepatotoxicity. J Hepatol 2005;43(5):901-10.

[4] Naranjo CA, Busto U, Sellers EM, et al. A method for estimating the probability of adverse drug reactions. Clin Pharmacol Ther 1981;30(2):239-45.

[5] Ajanal M, Nayak S, Prasad BS, et al. Adverse drug reaction and concepts of drug safety in Ayurveda: an overview. J Young Pharm 2013;5(4):116-20.

[6] Nayak S, Acharjya B. Adverse cutaneous drug reaction. Indian J Dermatol 2008;53(1):2-8.

[7] Sharma VK, Sethuraman G, Kumar B. Cutaneous adverse drug reactions: clinical pattern and causative agents--a 6 year series from Chandigarh, India. J Postgrad Med 2001;47(2):95-9.

[8] Pudukadan D, Thappa DM. Adverse cutaneous drug reactions: Clinical pattern and causative agents in a tertiary care center in South India. Indian J Dermatol Venereol Leprol 2004;70(1):20-4.

[9] Nandha R, Gupta A, Hashmi A. Cutaneous adverse drug reactions in a tertiary care teaching hospital: a North Indian perspective. Int J Appl Basic Med Res 2011;1(1):50-3.

[10] Mahatme N, Narasimharao R. A study of clinical patterns and causative agents of adverse cutaneous drug reactions. Indian J Drugs Dermatol 2016;2(1):13-8.

[11] Limbourg A, Steiert A, Jokuszies A, et al. Toxic epidermal necrolysis and natural remedies. $\mathrm{Br} \mathrm{J}$ Dermatol 2014;Dec;171(6):1583-5.

[12] Gilissen L, Huygens S, Goossens A. Allergic contact dermatitis caused by topical herbal remedies: importance of patch testing with the patients' own products. Contact Dermatitis 2018;78(3):177-84.
[13] Frenzel C, Teschke R. Herbal hepatotoxicity: clinical characteristics and listing compilation. Int J Mol Sci 2016;17(5):pii: E588.

[14] Asif M. A brief study of toxic effects of some medicinal herbs on kidney. Adv Biomed Res 2012;1:44.

[15] Zhu Y, Niu M, Chen J, et al. Hepatobiliary and pancreatic: comparison between Chinese herbal medicine and Western medicine-induced liver injury of 1985 patients. J Gastroenterol Hepatol 2016;31(8):1476-82.

[16] Philips CA, Paramaguru R, Joy AK, et al. Clinical outcomes, histopathological patterns and chemical analysis of Ayurveda and herbal medicine associated with severe liver injury-a single center experience from South India. Indian J Gastroenterol 2018;37(1):917.

[17] Loew D, Kaszkin M. Approaching the problem of bioequivalence of herbal medicinal products. Phytother Res 2002;16(8):705-11.

[18] Thatte U, Bhalerao S. Pharmacovigilance of ayurvedic medicines in India. Indian J Pharmacol 2008;40(Suppl 1):S10-2.

[19] Patwardhan K, Pathak J, Acharya R. Ayurveda formulations: A roadmap to address the safety concerns. J Ayurveda Integr Med 2017;8(4):279-82.

[20] Devarbhavi H. Ayurvedic and herbal medicine-induced liver injury: it is time to wake up and take notice. Indian J Gastroenterol 2018;37(1):5-7. 